\title{
Information and communication technology
} skills and resource utilization: preclinical versus clinical medical students in a resource-limited African setting

\author{
This article was published in the following Dove Press journal: \\ Open Access Bioinformatics \\ 19 April 2011 \\ Number of times this article has been viewed
}

\author{
Boniface Eze' \\ Anthony $\mathrm{Mba}^{2}$ \\ Francis Ozemena ${ }^{3}$ \\ 'Department of Ophthalmology, \\ ${ }^{2}$ Department of Pharmacology \\ and Therapeutics, ${ }^{3}$ Department of \\ Anatomy, University of Nigeria Enugu \\ Campus, Enugu, Nigeria
}

Objectives: To conduct a comparative assessment of information and communication technology (ICT) skills and resource utilization of preclinical and clinical medical students at the University of Nigeria.

Methods: Second- and fourth-year medical students of the University of Nigeria Enugu campus were participants in a comparative questionnaire-based cross-sectional survey between March 1 and April 30, 2010. Data on participants' demography, ICT skills, and resource uptake were captured in a questionnaire, and examined using descriptive and analytical statistics. The $P$-value was set at $P<0.05, d f=1$.

Results: The response rate was $93.9 \%$. The 462 participants (preclinical $=310$, clinical $=152$ ) comprised significantly more males, 318 (68.8\%), than females, $144(31.2 \%)(P<0.05)$ (gender ratio $=2.2: 1)$, aged $18-40$ years, with a mean age of 23.5 years \pm 3.69 SD. Significantly more of the clinical students than preclinical students had previous ICT training $(P<0.05)$, higher ICT skills $(P<0.05)$, ICT access $(P<0.05)$, and more frequently utilized ICT resources $(P<0.05)$ generally. Specifically, the clinical students had significantly higher ICT resource uptake for study $(P<0.05)$ and leisure $(P<0.05)$, but not for research $(P=0.565)$ than preclinical students.

Conclusions: The survey response rate was high. The cohorts varied widely in their ICT training, skills, access, and utilization. This has critical implications for the future design of the undergraduate medical curriculum. Incorporating ICT training into undergraduate medical training curriculum, and enhancement of ICT access is instructive. Further related research, preferably of longitudinal and multicenter design, is urgently needed.

Keywords: ICT, skills, resources, utilization, students, Nigeria

\section{Introduction}

The literature has continued to document phenomenal developments in the evolution, availability, ${ }^{2,3}$ and accessibility ${ }^{2,4}$ of information and communication technology (ICT), especially in the last two decades. These revolutionary changes have engendered a paradigm shift in teaching and learning in medicine, health research, and medical practice with resultant positive impacts on the output and uptake of qualitative medical care. ${ }^{5}$

Unfortunately, worldwide, there exist wide region-determined differences in ICT knowledge,${ }^{5,6}$ availability, ${ }^{4}$ and access,${ }^{7}$ occasioned by wide disparities in income and development between the North and South, termed the digital divide. Consequently, until recently, ICT-related activities in the teaching and practice of medicine have 
remained almost an exclusive preserve of developed countries, at the expense of the resource-constrained nations in the southern part of the digital divide. ${ }^{8}$ This has further widened the already precarious pro-North health care access disparity, and further alienated the resource-poor countries in critical need of ICT-enhanced indigenous research to generate evidence-based data on optimal approaches to teaching, learning, and practice of medicine. ${ }^{9}$

The established advantages of ICT-based (computerbased training-[CBT] and Web-based training-[WBT]) undergraduate medical training, comprising trainee-customized learning ${ }^{2,10}$ and multimedia capability, ${ }^{2}$ far outweigh its lack of interactivity ${ }^{2}$ and evaluation, ${ }^{10}$ often cited as its major drawbacks. Although fundamental to initiating a shift from traditional to ICT-based undergraduate medical education, provision of ICT infrastructure alone without backup strategies to overcome knowledge and attitude barriers to uptake of ICT resources has proved ineffective. ${ }^{4}$

Accurate mapping of medical students' baseline ICT knowledge and skills, the factors associated with their acquisition, and the available ICT resource are critical issues in the timing, scope, and modality of integrating ICT-based learning into their undergraduate medical training curriculum. ${ }^{8}$ Research reports on medical students' ICT literacy, access, and utilization have been dominated by reports, mainly descriptive, from surveys elsewhere outside Africa, ${ }^{10}$ with only a few studies conducted in Africa, namely, Nigeria, 2,11,12 Tanzania, ${ }^{4}$ and Sudan. ${ }^{7}$ Clearly, the research needed in this direction is urgent, especially in sub-Saharan Africa. The results of such surveys would provide the evidence base for results-oriented curricular changes incorporating ICT in the teaching and learning of undergraduate medicine.

To meet these research ends, the investigators embarked on a comparative survey of preclinical and clinical medical students at the University of Nigeria, Enugu campus, to assess their ICT knowledge and skills, ICT resource utilization, and the factors associated with these characteristics. The research data generated would assist planners and implementers of undergraduate medical training in Nigeria, and in similar settings elsewhere, to incorporate ICT learning into the curriculum. ${ }^{8}$

\section{Subjects and methods Background}

Established in 1960, Nigeria's first indigenous University, the University of Nigeria Nsukka, is located in Enugu state in the south-east geopolitical zone of Nigeria. Currently, the University has two campuses located in Nsukka, the parent campus, and Enugu. The University's medical school was established at the Enugu campus in 1971. Since establishment, the number of enrollees into the University's medical school has steadily increased from less than one hundred at inception to almost three hundred students per year. At the University of Nigeria, the duration of undergraduate medical training is six years; this comprises three years each of preclinical (preclerkship) and clinical (clerkship) training. The preclinical training period consists of an initial one-year premedical training, at the Nsukka campus, and an additional two years' training in basic medical sciences at Enugu campus. During the clinical training period, in addition to classroom-based lectures, students receive ward- and clinic-based clinical exposure at the University of Nigeria Teaching Hospital, relocated in 2007 from Enugu to Ituku-ozalla, about $20 \mathrm{~km}$ from Enugu town.

At present, medical students do not receive any official ICT training as part of their training curriculum. This resulted from the termination, prior to this survey, of medical students' ICT training contract between the University authority and Afrihub, an on-campus privately owned ICT resource provider. Of the two cohorts that participated in this survey, the fourth-year students (MD4), but not the second-year students (MD2), benefited from the official Afrihub-provided on-campus ICT training on basic computer skills, before the unfortunate termination of the training contract.

The ICT section of the University's medical library, still located in the hospital's old site in Enugu, has 16 functional Internet-enabled ICT work stations. Also, the two all-purpose university libraries, one each in Nsukka and Enugu campuses, are equipped with Internet-enabled ICT work stations.

\section{Ethics}

Prior to commencement of the study, ethical approval consistent with the tenets of the Helsinki Declaration was obtained from the Ethical Committee (Institutional Review Board) of the College of Medicine, University of Nigeria. Additionally, participants' informed consent to participation was obtained prior to enrollment into the study.

The survey objectives were to perform a comparative assessment of ICT knowledge and skills, resource utilization, and attitudes of preclinical (MD2) and clinical (MD4) medical students at the University of Nigeria.

\section{Settings}

The study was a comparative questionnaire-based survey of MD2 and MD4 medical students conducted at the College of Medicine, University of Nigeria Enugu campus, between March 1 and April 30, 2010. 


\section{Questionnaire development}

The study instrument, adapted from three previous surveys, $2,4,10$ was a self-administered structured questionnaire. To ascertain the face, flow, and interpretation, the study questionnaire was pretested on a cohort of first- (MD1) and fifth- (MD5) year medical students at the study center. The participants in the pretest were not scheduled for inclusion in the final survey. The modifications of content and design of the questionnaire, suggested by the pretest, were implemented after consensus by all the investigators.

The final version of the questionnaire (see Appendix) has five fields, including the participants' demographics; ICT skills; ICT resource availability and utilization; e-learning exposure; and attitudes to e-learning, its usefulness, and its current and potential roles in undergraduate medical education.

Of interest to the study were baseline data on participants' demographics: age, sex, and year of study. Prior to assessment of the participants' ICT skills profile, the skills were categorized into generic and specific ICT skills. The generic ICT skills $(n=10)$ comprised word processing, Windows, file management, programming, software installation, graphics - presentation and MS Power Point, spreadsheet, database use, email, and web browsing. The specific ICT skills $(n=10)$ of interest were: print out a document, cut and paste information, draw and paint, use organizer, set up mail box, learn new applications, analyze data with a statistical package, games, online discussions, and Web-page design.

In the self-assessment of generic and specific ICT skills proficiency, the participants' responses were structured on a 4-point Likert scale, ie, $0=$ do not know how to use it, $1=$ some elementary skills, $2=$ can use it but want to learn more, $3=$ my skills are okay. The elicited responses were subsequently dichotomized and reduced to proportions by categorizing participants' scores of $0-1$ as unsatisfactory, and $2-3$ as satisfactory skills proficiencies. The field on ICT resource availability and utilization explored the participants' available ICT resource with respect to type, access pattern, and frequency of utilization. Responses on the frequency of ICT resource utilization were formatted on a 4-point (0-3) Likert scale and later recoded into frequent $(0-1)$ and infrequent (2-3) resource uptake subgroups.

Finally, participants' exposure to different e-learning programs such as image repositories, hypertexts, simulations, quizzes, animations, encyclopedias, forum, and learning management systems, their opinions on the usefulness of these programs, and the preferred role/s of e-learning in undergraduate medical education were assessed.

\section{Survey administration}

To enhance survey participation rate, the investigators collaborated with the class representatives of the MD2 and MD4 classes to obtain an accurate class register and decide on the optimal time and venue for conducting the survey. Clarifications in the questionnaire, where needed, were made by the researchers who were physically present during the survey.

\section{Data analysis}

Data were analyzed using the SPSS software (v 18.0, SPSS Inc, Chicago, IL). Data entry accuracy was ascertained by re-entering data in 20 randomly selected filled study questionnaires. Descriptive statistical examination of entered data yielded percentages, frequencies, and proportions. Analytical statistical tests for significant betweenclass differences were performed using the chi-square test. Student's $t$-test was used for comparison of means. A two-sided $P$-value $<0.05$ (with one degree of freedom) was considered statistically significant.

\section{Results}

Of an enrolled sample of 492 medical students, comprising $327 \mathrm{MD} 2 \mathrm{~s}$ and $165 \mathrm{MD} 4 \mathrm{~s}, 462(\mathrm{MD} 2=310, \mathrm{MD} 4=152)$ students who responded to the survey constituted the examined sample. The survey response rates were MD2, 94.8\% (310/327), MD4, 92.1\% (152/165), and 93.9\% (462/492) overall. There was no significant inter-class difference in response rate (MD2 vs MD4: $94.8 \%$ vs $92.1 \%, P=0.05$ ).

\section{Demographic characteristics}

Overall, the participants comprised 318 (68.8\%) males and $144(31.2 \%)$ females (gender ratio $=2.2: 1)$, aged $18-40$ years, with a mean age of 23.5 years \pm 3.69 SD. Analysis of intra-class demographic characteristics showed that MD2 consisted of $223(79.1 \%)$ males and 87 (28.1\%) females $($ sex ratio $=2.7: 1)$, aged $18-36$ years, with a mean age of 22.5 years \pm 3.6 SD. Similarly, MD4 class comprised 95 $(62.5 \%)$ males and $57(37.5 \%)$ females (sex ratio $=1.7: 1)$ aged 20-40 years, with a mean age of 25.6 years \pm 2.9 SD. There were significant inter-class differences in gender ( $71.9 \%$ vs $62.5 \%, P<0.05)$, and mean age (22.5 years \pm 3.6 SD vs 25.6 years $\pm 2.9 \mathrm{SD}, t=9.28, P<0.05)$. The participants' demographic characteristics are shown in Table 1.

\section{ICT training, literacy, and skills}

All the MD4s (100.0\%), but none of the MD2s (0.0\%), received the University-sponsored formal ICT training. However, some respondents (MD2, 41.7\%, MD4, 58.6\%) 
Table I Demographic characteristics of 310 preclinical [year 2, MD2] and I52 clinical [year 4, MD4] medical students

\begin{tabular}{|c|c|c|c|c|c|}
\hline \multirow[t]{2}{*}{ Age (years) } & \multicolumn{2}{|c|}{$\begin{array}{l}\text { Preclinical [MD2] } \\
n=310\end{array}$} & \multicolumn{2}{|c|}{$\begin{array}{l}\text { Clinical [MD4] } \\
n=152\end{array}$} & \multirow[t]{2}{*}{$\begin{array}{l}\text { Total (\%) } \\
n=462\end{array}$} \\
\hline & $M$ & $\mathbf{F}$ & $M$ & $\mathbf{F}$ & \\
\hline $16-20$ & 52 & 48 & 4 & 1 & $105(22.7)$ \\
\hline $21-25$ & 129 & 34 & 44 & 41 & $248(53.7)$ \\
\hline $26-30$ & 36 & 4 & 43 & 12 & $95(20.6)$ \\
\hline $31-35$ & 2 & 0 & 3 & 2 & $7(1.5)$ \\
\hline $36-40$ & 4 & I & 1 & I & $7(1.5)$ \\
\hline Total (\%) & $223(48.3)$ & 87 (I8.8) & $95(20.6)$ & $57(12.3)$ & $462(100.0)$ \\
\hline
\end{tabular}

received privately arranged formal ICT training comprising basic word processing, email, and web browsing. Additionally, $44.4 \%$ of MD2s and $38.2 \%$ of MD4s had informal ICT training through peer- or cyber cafe operatorassisted ICT skills acquisition, or both. The inter-group difference in formal ICT training status was statistically significant (41.7\% vs $100.0 \% P<0.05)$. All $(100.0 \%)$ the study participants were computer literate; however, to a highly variable degree. Of the 10 areas of generic ICT skills assessed, the MD4s were significantly (all $P$ values $<0.05$ ) more proficient than their MD2 counterparts in nine areas; however, there was no significant between-class difference in the participants' self-assessed proficiency in computer programming $(P=0.622)$.

While the MD4s were more proficient in four (all $P<0.05$ ) of the seven non-Internet-based specific ICT skills, the Internet-based specific ICT skills proficiency status did not differ significantly between the two study cohorts: set up mail box $(P=0.268)$, online discussion $(P=0.359)$, and web-page design $(P=0.23)$. The ICT skills profile is shown in Table 2.

Further intra-group analysis by sex showed significant pro-male gender differences in at least half of the ICT skills areas assessed: MD2s (males vs females, $64.5 \%$ vs $48.0 \%$, $P<0.05)$ and MD4s $(51.0 \%$ vs $36.8 \%, P<0.05)$.

\section{Availability and utilization of ICT resources}

The public pay-as-you-go cyber café and institutional libraries were the main access points for Internet resource (MD2, MD4: 71.0\%, 64.5\%). The majority of the respondents $(66.7 \%, 68.4 \%)$ could not identify the category of the Internet service they utilized, ie, broadband and or others; hence the efficiency of the utilized Internet resource could not be reliably assessed. In addition to their significantly greater access to computer infrastructure $(92.7 \%$ vs $98.0 \%$, $P<0.05)$, the MD4s were significantly more likely to own a personal computer $(23.5 \%$ vs $72.4 \%, P<0.05)$. There was no significant difference in their access to the Internet (98.4\% vs 98.7\%, $P=0.806)$. Compared with their MD2 colleagues, the MD4 students had a significantly higher mean age at first use of computer $(14.8 \pm 5.8 \mathrm{SD}$ vs $16.7 \pm 4.7$ $\mathrm{SD}, t=3.52, P<0.05)$, and tended to spend more hours per week doing computer work $(6.15$ hours \pm 10.89 SD vs 11.78 hours $\pm 17.06 \mathrm{SD}, t=4.40, P<0.05)$. The reasons for ICT resource utilization were study $(41.0 \%$ vs $66.4 \%$, $P<0.05)$, leisure (51.0\% vs $36.8 \%, P<0.05)$, and research (41.6\% vs 38.8\%, $P=0.565)$. But for use of computer games (64.5\% vs $48.0 \%, P<0.05)$, the study cohorts did not differ significantly in the frequency of utilization of non-Internetbased e-resources (all $P>0.05$ ); however, the MD4s significantly more frequently accessed Internet-based e-resources (all $P<0.05$ ) (Table 3).

The frequency of utilization of online medical e-information resources showed the following pattern: PubMed/Medline (43.5\%, 55.9\%, $P<0.05)$, Google Scholar (44.2\%, 53.9\%, $P<0.05)$, Cochrane Library (39.7\%, 46.1\%, $P=0.1917)$, full text articles online $(51.9 \%, 55.9 \%, P=0.42)$, and advanced use of the World Wide Web $(48.7 \%, 59.2 \%, P<0.05)$.

\section{Attitudes to e-learning}

The MD2s and MD4s did not differ significantly in their appraisal of the usefulness of the various e-learning programs (all $P>0.05$ ) (data not shown); however, while encyclopedias were most frequently rated as most useful by the MD2s (17.4\%), hypertext was most frequently selected as the most useful e-learning tool by the MD4s (21.7\%). Similarly, no significant inter-group differences were observed in the participants' opinion on the need for e-learning programs $(21.6 \%$ vs $21.7 \%, P=0.245)$ and their potential for lecture substitution $(31.3 \%$ vs $23.7 \%, P=0.09)$ or lecture supplementation (55.2\% vs $61.8 \%, P=0.173$ ); and the appropriateness of their current role in undergraduate medical education $(61.9 \%$ vs $64.5 \%, P=0.596)$. 
Table 2 Proficiency profile of ICT skills of medical students

\begin{tabular}{|c|c|c|c|c|}
\hline \multirow[t]{2}{*}{ ICT skill } & \multicolumn{2}{|c|}{ Proportion proficient in skill } & \multirow[t]{2}{*}{ Chi-square } & \multirow[t]{2}{*}{$P$-value } \\
\hline & $\begin{array}{l}\text { Preclinical }(n=3 \mid 0) \\
n(\%)\end{array}$ & $\begin{array}{l}\text { Clinical }(n=152) \\
n(\%)\end{array}$ & & \\
\hline \multicolumn{5}{|l|}{ Generic ICT skills } \\
\hline Word processing & I 48 (47.7) & $109(71.7)$ & 23.74 & $<0.000 I^{*}$ \\
\hline Windows & $215(69.4)$ & $138(90.8)$ & 25.99 & $<0.000 I^{*}$ \\
\hline File management & $186(60.0)$ & $|2|(79.6)$ & 17.58 & $<0.000 I^{*}$ \\
\hline Programming & $15(4.8)$ & $9(5.9)$ & 0.2426 & 0.6223 \\
\hline Software installation & $136(43.9)$ & $86(56.6)$ & 6.598 & $0.0102 *$ \\
\hline Database use & $152(49.0)$ & $94(6 \mid .8)$ & 6.723 & $0.0095 *$ \\
\hline Graphics & $158(5 \mid .0)$ & $128(84.2)$ & 47.79 & $<0.000 I^{*}$ \\
\hline Spreadsheet & I 47 (47.4) & $124(8 \mid .6)$ & 49.08 & $<0.000 I^{*}$ \\
\hline Email & $208(67.1)$ & $132(86.8)$ & 20.46 & $<0.000 I^{*}$ \\
\hline Web browsing & $202(65.2)$ & $127(83.6)$ & 16.83 & $<0.000 I^{*}$ \\
\hline \multicolumn{5}{|l|}{ Specific ICT skills } \\
\hline Print out a document & $162(52.3)$ & $100(65.8)$ & 7.607 & $0.0058^{*}$ \\
\hline Cut and paste information & $248(80.0)$ & $112(73.7)$ & 2.365 & 0.1241 \\
\hline Draw and paint & 147 (47.4) & $74(48.7)$ & 0.1435 & 0.7048 \\
\hline Organizer & 117 (37.7) & $56(36.8)$ & 0.03526 & 0.8511 \\
\hline Learn new applications & $153(49.4)$ & $92(60.5)$ & 5.110 & $0.0238^{*}$ \\
\hline Statistical software & $113(36.5)$ & 7I (46.7) & 4.479 & $0.0343 *$ \\
\hline Games & $187(60.3)$ & II 8 (77.6) & 13.62 & $0.0002 *$ \\
\hline Set up mail box & $278(89.7)$ & $|3|(86.2)$ & 1.225 & 0.2683 \\
\hline Online discussions ${ }^{\mathrm{a}}$ & $198(63.9)$ & $123(80.9)$ & 0.8424 & 0.3587 \\
\hline Web-page design & $92(29.7)$ & $37(24.3)$ & $\mathrm{I} .443$ & 0.2297 \\
\hline
\end{tabular}

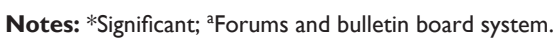

\section{Discussion}

The $93.9 \%$ overall response rate in the present study is comparable with Ajuwon's report in Nigeria of $100.0 \%{ }^{2}$ but differed markedly from the rates reported in another Nigerian survey, $79.0 \%,{ }^{11}$ and elsewhere in Tanzania, $72.7 \%{ }^{4}$ Austria, 79.0\%; ${ }^{6}$ Jordan, $81.0 \% ;{ }^{10}$ and USA, $81.0 \% .{ }^{13}$ In addition to the use of class time for the survey, as suggested by Link and Marz, ${ }^{6}$ the participants' pre-survey motivation and survey flexibility on the timing of the return of filled questionnaires probably further enhanced the response rate. This suggests the adoption of similar strategies by investigators planning future similar surveys. Similar to previous reports in Nigeria, ${ }^{2,11}$ but in contrast with the findings of the Austrian ${ }^{6}$ and the Jordanian ${ }^{10}$ surveys, the gender characteristics of the survey participants revealed a pro-male gender disparity. The age characteristics of the study cohorts differed from the findings in Nigeria ${ }^{2,11}$ and in other ${ }^{6,10}$ surveys. Between-survey differences in participants' course status, and by extension age, and inter-regional variations of university entry age probably account for the observed age differences. Similar to Ajuwon, ${ }^{2}$ Link and Marz ${ }^{6}$ studied first-year medical students; Ameh and Ameh ${ }^{11}$ reported on clinical (clerkship) students while Rajab and Baqain's ${ }^{10}$ cohort comprised second- to fifth-year students. Further, in Nigeria, unlike the situation elsewhere, ${ }^{6,10}$ frequent disruptions in academic calendar due to industrial actions by the universities' academic staff prolong the duration of undergraduate training and create a mismatch between course status and candidate age. These may explain the observed age differences. The gender inequity observed in the present survey, and probably in other Nigerian surveys, ${ }^{2,11}$ reflects a probable male dominance in enrollment into Nigerian medical schools. This is probably not the case in Austria ${ }^{6}$ and Jordan. ${ }^{10}$

The observed gender distribution suggests the existence of a local gender-sensitive access barrier to undergraduate medical education in Nigeria, and has critical implications for the future gender composition of the medical workforce. The authors recommend vocational guidance/counseling and the government's active motivational interventions, through the awarding of scholarships, to attract potential female enrollees into medical schools.

The study participants displayed high, but widely variable, levels of ICT literacy and training, with the clinical students having a definite advantage over their preclinical counterparts in both generic and specific ICT skills. Also, significant pro-male gender ICT skills disparities were present in the two groups. The ICT literacy level observed in the present survey is comparable with the findings by Rajab and Baqain ${ }^{10}$ 
Table 3 Pattern of ICT resource utilization by medical students

\begin{tabular}{|c|c|c|c|c|}
\hline ICT resource & $\begin{array}{l}\text { Preclinical (MD2, } n=310) \\
\text { n (\%) }\end{array}$ & $\begin{array}{l}\text { Clinical (MD4, n = I52) } \\
\text { n (\%) }\end{array}$ & Chi-square & $P$-value \\
\hline & \multicolumn{4}{|c|}{ Proportion utilizing resource frequently } \\
\hline MS Word & $173(55.8)$ & $77(50.7)$ & 1.089 & 0.2967 \\
\hline MS Excel & $221(71.3)$ & $117(77.0)$ & 1.678 & 0.1952 \\
\hline Organizer & $211(68.1)$ & $105(69.1)$ & 0.0485 & 0.8256 \\
\hline Draw and paint & $182(58.7)$ & $90(59.2)$ & 0.01057 & 0.9181 \\
\hline Charts & $184(59.4)$ & $84(55.3)$ & 0.7010 & 0.4024 \\
\hline Games & $200(64.5)$ & $73(48.0)$ & 11.47 & $0.0007^{*}$ \\
\hline Email & $168(45.2)$ & $50(32.9)$ & 18.7 & $<0.000 I^{*}$ \\
\hline Online discussions & $200(64.5)$ & $118(77.6)$ & 8.178 & $0.0042 *$ \\
\hline \multicolumn{2}{|l|}{ information } & $33(21.7)$ & 7.919 & $0.0049 *$ \\
\hline E-learning program & \multicolumn{4}{|c|}{ Proportion who had used it at least once } \\
\hline Image repositories & $59(19.0)$ & $27(17.8)$ & 0.1084 & 0.7419 \\
\hline Hypertext & $96(31.0)$ & $74(48.7)$ & 13.6 & $0.0002^{*}$ \\
\hline Simulations & $34(11.0)$ & $22(14.5)$ & 1.17 & 0.2780 \\
\hline Quizzes & $91(29.4)$ & $55(36.2)$ & 2.201 & 0.1379 \\
\hline Animations & $80(25.8)$ & $46(30.3)$ & 1.021 & 0.3122 \\
\hline Encyclopedias & $142(45.8)$ & $86(56.6)$ & 4.735 & 0.0296 \\
\hline $\begin{array}{l}\text { Forum for communicating } \\
\text { with other students }\end{array}$ & $92(29.7)$ & $36(23.7)$ & 1.829 & 0.1762 \\
\hline Learning management systems & $45(14.5)$ & $18(11.8)$ & 0.623 & 0.431 \\
\hline
\end{tabular}

Note: *Significant.

but differed from the observations of Ajuwon, ${ }^{2}$ Ameh and Ameh, ${ }^{11}$ and Odusanya and Bamgbala, ${ }^{12}$ all in Nigeria. Whereas the similarity in study settings, and partial similarity in ICT training exposure, between the present survey and that of Rajab and associates ${ }^{10}$ may explain the similarity of the survey results, the time interval between studies, especially as it affects the ICT revolution, ${ }^{3}$ probably accounts for the wide discrepancy with previous Nigerian surveys.

Furthermore, although not evaluated in the present survey, disparities in respondents' parental income may partly account for the observed wide variations in their ICT access and skills. The respondents' high ICT literacy level, partly attributable to the mandatory MD4s' curricular ICT training, has favorable implications for the integration of ICT into medical training and suggests the need for mandatory ICT exposure in the undergraduate medical curriculum. The preclinical students' bias in ICT skills profile in the present report echoes the findings in Jordan, ${ }^{10}$ partially agrees with the reports in Tanzania ${ }^{4}$ and Nigeria, ${ }^{11}$ and contrasts with the low ICT skills of final-year medical students reported in Lagos, Nigeria. ${ }^{1}$ The clinical students' greater ICT need for routine academic and clinical activities ${ }^{10}$ likely fired their zeal to acquire the necessary ICT skills to satisfy these needs. This, coupled with the previous ICT curricular training exposure of the clinical participants in the present study, probably explain the observations. While the Tanzanian ${ }^{4}$ and Nigerian ${ }^{11,12}$ surveys were descriptive studies of clinical students, the present communication is on a comparative survey of preclinical and clinical students, hence the partial comparison of the survey findings. Consistent with reports elsewhere, ${ }^{5,6,10}$ and in keeping with the natural trend among students in the health professions, ${ }^{14}$ the male respondents had higher ICT skills than females. Beyond the pro-male gender bias in ICT access, results from previous surveys ${ }^{6,14}$ have established a comparatively higher attitudinal disposition of males toward ICT. These likely explain the observed gender differences in ICT skills. The present data seem to suggest a paradigm shift in curricular content to ensure early introduction, and continuous ICT training to sustain acquired skills, during undergraduate medical training. Additionally, curriculum planners and implementers should identify and overcome factors underlying gender inequity in ICT skills.

Compared with the preclinical students, the clinical students were significantly older at first use of computers, had higher access to computers, and accessed ICT resources more frequently for study and leisure, but not for research; also, they significantly more frequently utilized most of the available offline and online ICT resources. The mean ages at first computer use in the two groups were higher than the overall and sex-specific mean ages reported by Link and Marz $^{6}$ in Austria. However, the lack of information on this fundamental ICT parameter from previous similar reports 
in Nigeria, ${ }^{2,11,12}$ and majority of reports elsewhere, ${ }^{1-5,7-11}$ precluded further between-survey comparisons. Differences in extracurricular factors, operating before the individual's university admission, such as parental literacy level and socioeconomic status, ICT access at place of residence, and ICT content of pre-university education, could explain the observed discrepancy in the mean ages at first computer use. The disparity in ICT access across the North-South digital divide, ${ }^{4-7}$ grossly biased in favor of the North, likely explains the differences between the mean ages in the present report and the Austrian survey. The pro-MD4 disparity in access to computer infrastructure, but not the Internet, corroborates the observations by Romavov and Aarnio ${ }^{15}$ that clinical students, spurred by their comparatively greater need for independent work and intensive clinical perspective, had greater access to ICT resources. Beyond this, the higher ICT knowledge profile of MD4s probably motivated them to acquire ICT access.

The observed lack of agreement between computer and Internet access suggests that most of the computer access points, utilized by the MD4s, are not Internet-enabled. To bridge the gap in ICT access, Ajuwon ${ }^{2}$ suggested the extension of soft computer loans, similarly recommended by Iliyasu et $\mathrm{al}^{5}$ for health workers, to medical students. The comparatively more frequent study- and leisure-related, but not research-related, ICT resource uptake of clinical students is consistent with the Finnish ${ }^{15}$ report but differed from the observations in Jordan. ${ }^{10}$ While the higher ICT access of clinical students may explain their greater use of ICT for leisure and study, the general apathy towards research among medical students and faculties in developing countries ${ }^{16}$ probably accounts for the uniform pattern of research-related ICT resource underutilization. The observed pattern of ICT resource utilization is most likely a consequence of the differential distribution of ICT access, ${ }^{5}$ which favored the clinical students, and re-emphasizes the need to implement the measures initially recommended for bridging the ICT access gap.

Although there were no significant inter-class differences in participants' opinions on the role and potential of e-learning in undergraduate medical education, the majority of preclinical and clinical students felt that e-learning should play a larger role, especially in supplementing lectures. Although in agreement, the observations cannot be validly compared with the findings by Dorup ${ }^{3}$ and Iliyasu and associates $^{5}$ due to between-survey differences in study design and participants' characteristics, respectively. The observed positive attitude towards e-learning implies the presence of an enabling background mental environment for future integration of e-learning into the existing undergraduate medical training curriculum, if the needed resources are available.

The conclusions drawn from this study are limited by its self-report design, and the universal lack of direct measures of ICT literacy, and the questionable validity of such measurements over time. ${ }^{3}$ Further, the inherent pro-male gender bias in reporting self-assessed efficacy generally, and the tendency for males to overestimate their ICT capabilities ${ }^{6,15,17}$ specifically, present additional limitations. The cross-sectional and single-center nature of the present survey constitute further limitations to the temporal and spatial extrapolation of the survey results.

\section{Conclusions}

The survey response rate was high. The participants had widely variable levels of ICT training and skills. Comparatively, the clinical students tended to have more access, and utilized offline, but not online, e-resources significantly more frequently for study and leisure. Although the majority of each class suggested there was a greater role for e-learning and accepted it as a lecture supplement, there were no significant between-class differences in participants' attitudes to e-learning. These results have implications for planners and implementers of undergraduate medical training in resourcepoor settings, and highlight the need to equip medical undergraduates, through formal ICT training, with appropriate ICT knowledge, skills, and attitudes, and to identify and overcome their perceived barriers to ICT access. To further extend the horizon of knowledge in ICT, the authors suggest that similar studies in the future should adopt a longitudinal and multicenter design.

\section{Acknowledgments}

The authors wish to acknowledge the assistance of staff and students of the College of Medicine, University of Nigeria, Enugu Campus.

\section{Disclosure}

The authors report no conflicts of interest in this work.

\section{References}

1. Millman A, Lee N, Kealy K. ABC of medical computing and the internet. BMJ. 1995;311:440.

2. Ajuwon GA. Computer and internet use by first year clinical and nursing students in a Nigerian teaching hospital. BMC Med Inform Decis Mak. 2003;3:10.

3. Dorup J. Experience and attitudes towards information technology among first year medical students in Denmark: longitudinal study. J Med Internet Res. 2004;6:e10. 
4. Samuel M, Coombes JC, Miranda JJ, Melvin R, Young EJW, Azarmina P. Assessing computer skills in Tanzanian medical students: an elective experience. BMC Public Health. 2004;4:37.

5. Iliyasu Z, Abubakar IS, Kabir M, Abbas SM. Computing knowledge, attitudes and skills among healthcare professionals in Aminu Kano teaching Hospital, Nigeria. Nig J Med. 2005;14:200-205.

6. Link TM, Marz R. Computer literacy and attitudes towards e-learning among first year medical students. BMC Med Educ. 2006;6:34.

7. Ahmed AM, Yousif E, Abdalla ME. Use of the internet by Sudanese doctors and medical students. East Mediterr Health J. 2008;14:134-141.

8. Seago BL, Schlensinger BJ, Hampton CL. Using a decade of data on medical student computer literacy for strategic planning. J Med Libr Assoc. 2002;90:202-209.

9. Sadana R, D'souza C, Hyder AA, Chowdhurry RM. Importance of health research in South Asia. BMJ. 2004;328:826-830.

10. Rajab LD, Baqain ZH. Use of information and communication technology among dental students at the University of Jordan. J Dent Educ. 2005;69:387-398

11. Ameh N, Ameh EA. Computer knowledge amongst clinical year medical students in a resource-poor setting. Afr Health Sci. 2008;8:40-43.
12. Odusanya $\mathrm{O}$, Bamgbala $\mathrm{O}$. Computing and information technology skills of final year medical and dental students at the College of Medicine, University of Lagos, Nigeria. Niger Post Grad Med J. 2002;9: 189-193.

13. Seago BL, Schesinger JB, Hamptom CL. Using a decade of data on medical student computer literacy for strategic planning. J Med Libr Assoc. 2002;90:202-209.

14. Wilkinson A, Allison E, Roberts W, Roberts J. Measurement of communication and information technology experience and attitudes to e-learning of students in the health care profession: integrative review. JAdvNurs. 2009;65:755-772.

15. Romavov K, Aarnio M. A survey of the use of electronic information resources among medical and dental students. BMC Med Educ. 2006;6:28.

16. Sadana R, D'souza C, Hyder AA, Chowdhurry RM. Importance of health research in South Asia. BMJ. 2004;328:826-830.

17. Bakkin LL, Sheridan J, Carnes M. Gender differences among physicianscientists in self-assessed abilities to perform clinical research. Acad Med. 2003;78:1281-1285. 


\section{Appendix}

Information and communication technology literacy and resource utilization survey

We are conducting the above investigator-funded study on preclinical and clinical medical students of University of Nigeria Enugu campus. Participation is voluntary. The investigators guarantee the anonymity of your participation and the confidentiality of your response. Unless otherwise instructed by participant, the data provided would be used strictly for academic purposes.

Instructions: Kindly fill in the appropriate data or tick good against the correct option/s in the spaces provided.

\section{Demographics}

1. Age (in completed years):

2. Sex: (a) Male ( ) (b) Female ( )

3. Course status (year of study)

\section{ICT training and skills}

4. Any previous ICT training? (a) Yes ( ) (b) No ( )

5. If Yes, what type of training? (a) formal university-sponsored training ( ) (b) formal privately arranged training ( ) (c) Informal training ( )

6. Are you computer literate? (a) Yes ( ) (b) No ( )

7. If No, reason for computer illiteracy. (a) Lack of time () (b) No access ( ) (c) Not interested () (d) No reason ()

8. ICT skills

\section{Generic ICT skills}

On a scale of $0-3(0=$ do not know how to use it, $1=$ some elementary skills, $2=$ can use it but want to learn more, 3 = my skills are okay), rate your proficiency in the use of the following:

\begin{tabular}{|l|c|c|c|c|}
\hline \multirow{2}{*}{ Skills } & \multicolumn{4}{|c|}{$\begin{array}{c}\text { Your competence (tick one } \\
\text { box for each skill) }\end{array}$} \\
\cline { 2 - 5 } & $\mathbf{0}$ & $\mathbf{I}$ & $\mathbf{2}$ & $\mathbf{3}$ \\
\hline Word processing & & & & \\
\hline Windows & & & & \\
\hline File management & & & & \\
\hline Programming & & & & \\
\hline $\begin{array}{l}\text { Graphics- Presentation } \\
\text { and Powerpoint }\end{array}$ & & & & \\
\hline Software installation & & & & \\
\hline Spreadsheet & & & & \\
\hline $\begin{array}{l}\text { Database - use } \\
\text { existing one }\end{array}$ & & & & \\
\hline E-mail & & & & \\
\hline Web browsing & & & & \\
\hline
\end{tabular}

\section{Specific ICT skills}

\begin{tabular}{|l|c|c|c|c|}
\hline \multirow{2}{*}{ Skills } & \multicolumn{4}{|c|}{$\begin{array}{c}\text { Your competence (tick one } \\
\text { box for each skill) }\end{array}$} \\
\cline { 2 - 5 } & $\mathbf{0}$ & $\mathbf{I}$ & $\mathbf{2}$ & $\mathbf{3}$ \\
\hline Print out a document & & & & \\
\hline Cut and paste information & & & & \\
\hline Draw and paint & & & & \\
\hline Learn new applications & & & & \\
\hline Use statistical package & & & & \\
\hline Games & & & & \\
\hline Organizer & & & & \\
\hline Set up mail box & & & & \\
\hline Online discussions & & & & \\
\hline Web page design & & & & \\
\hline
\end{tabular}

\section{ICT resource availability and utilisation}

9. What is your main access to computer? (a) personal computer ( ) (b) family computer ( ) (c) public computer room ie, cyber café ( ) (d) not at all ( )

10. How old were you when you started using the computer for the first time? years.

11. If you own a personal computer, how old is the computer? (a) $<1$ year ( ) (b) 1-3 years (c ) 4-5 years ( ) (d) $>5$ years ( )

12. What is your main access to the Internet? (a) personal Internet connection ( ) (b) Family Internet connection ( ) (c) Cyber café ( ) (c) Not at all ( )

13. What type of Internet access do you use regularly? (a) Modem/ISDN (telephone line) ( ) (b) Cable/ADSL or another type of Broad Band Internet ( ) (c) LAN ie, local area network (as in public computer rooms/cyber café () (d) do not know ( ) (e) None ()

14. In the past one year, how many hours per week do you regularly spend doing computer work? hrs.

15. Rate the frequency of your use of ICT for the following activities:

\begin{tabular}{|l|c|c|c|c|}
\hline \multirow{2}{*}{$\begin{array}{l}\text { ICT } \\
\text { activity }\end{array}$} & \multicolumn{4}{|c|}{ Frequency of use } \\
\cline { 2 - 5 } & $\begin{array}{c}\mathbf{0} \\
\text { (never) }\end{array}$ & $\begin{array}{c}\text { I } \\
\text { Seldom } \\
(\mathbf{I - 7} \text { times/ } \\
\text { semester })\end{array}$ & $\begin{array}{c}\mathbf{2} \\
\text { Quiet often } \\
(2-7 \text { times/ } \\
\text { month) }\end{array}$ & $\begin{array}{c}\text { Very often } \\
\text { ( } \geq 2 \text { times/ } \\
\text { week })\end{array}$ \\
\hline Study & & & & \\
\hline Research & & & & \\
\hline Leisure & & & & \\
\hline
\end{tabular}


16. Rate the frequency of your utilization of the following ICT resources:

\begin{tabular}{|l|l|l|l|l|}
\hline \multirow{2}{*}{ ICT resource } & \multicolumn{4}{|c|}{ Frequency of use } \\
\cline { 2 - 5 } & $\begin{array}{c}\mathbf{0} \\
\text { (never) }\end{array}$ & $\begin{array}{c}\text { I } \\
\text { Seldom } \\
\text { (I-7 times/ } \\
\text { semester) }\end{array}$ & $\begin{array}{c}\mathbf{2} \\
\text { Quiet often } \\
\text { (2-7 times/ } \\
\text { month) }\end{array}$ & $\begin{array}{c}\text { 3 } \\
\text { Very often } \\
\text { ( } \geq \text { 2 times/ } \\
\text { week) }\end{array}$ \\
\hline MS Word & & & & \\
\hline Organizer & & & & \\
\hline Spread sheet & & & & \\
\hline Draw and paint & & & & \\
\hline Games & & & & \\
\hline E-mail & & & & \\
\hline Charts & & & & \\
\hline $\begin{array}{l}\text { Online } \\
\text { discussions }\end{array}$ & & & & \\
\hline $\begin{array}{l}\text { Search the } \\
\text { Internet for } \\
\text { medical } \\
\text { information }\end{array}$ & & & & \\
\hline
\end{tabular}

17. Rate the frequency with which you access the following e-information sources:

\begin{tabular}{|c|c|c|c|c|}
\hline \multirow{2}{*}{$\begin{array}{l}\text { E-information } \\
\text { source }\end{array}$} & \multicolumn{4}{|c|}{ Frequency of use } \\
\hline & $\begin{array}{c}0 \\
\text { (never) }\end{array}$ & $\begin{array}{c}\text { I } \\
\text { Seldom } \\
(\text { I-7 times/ } \\
\text { semester })\end{array}$ & $\begin{array}{c}2 \\
\text { Quiet } \\
\text { often } \\
\text { (2-7 times/ } \\
\text { month) }\end{array}$ & $\begin{array}{c}3 \\
\text { Very } \\
\text { often } \\
\text { ( } \geq 2 \text { times } \\
\text { week) }\end{array}$ \\
\hline $\begin{array}{l}\text { Medline (PubMed } \\
\text { or Ovid) }\end{array}$ & & & & \\
\hline Google scholar & & & & \\
\hline $\begin{array}{l}\text { Cochrane } \\
\text { Library }\end{array}$ & & & & \\
\hline $\begin{array}{l}\text { Full-text articles } \\
\text { online }\end{array}$ & & & & \\
\hline
\end{tabular}

18. Different types of e-learning programs exist. With which of these have you worked? Tick $\sqrt{ }$ as appropriate.

(a) Image repositories (usually containing little explanatory text) ( )

(b) Hypertexts (eg, web-based text books) ( ) (c) Simulations (eg, patient or simulations) ( )

(d) Quizzes (eg, question repositories with assessment) ( )

(e) Animations (eg, computer animations that offer some user interaction ( )

(f) Encyclopedias (eg, online Psychoremble) ( )

(g) Forum for communicating with other students ( )

(h) Learning management systems (portals for hosting web-based courses) ( )

\section{Attitudes towards e-learning}

19. Which of these do you consider most useful for e-learning? Select one option.

(a) Image repositories (usually containing little explanatory text) ( )

(b) Hypertexts (eg, web-based textbooks) ()

(c) Simulations (eg, patient or simulations) ()

(d) Quizzes (eg, question repositories with assessment) ()

(e) Animations (eg, computer animations that offer some user interaction ()

(f) Encyclopedias (eg, online Psychoremble) ( )

(g) Forum for communicating with other students ( )

(h) Learning management systems (portals for hosting web-based courses ( )

20. Using the code ( $\mathrm{A}=\mathrm{I}$ agree, $\mathrm{N}=$ neutral, $\mathrm{D}=\mathrm{I}$ disagree), react to the following statements concerning e-training [computer - based training (CBT) and web-based training $(\mathrm{CBT})]$.

(a) Computer - or web-based training should play a more important role ( )

(b) Web-based learning programs are able to replace lecture ()

(c) In medical training, there is no need for web-based programes ()

(d) Computer and web-based training should supplement lectures and exercises ( )

(e) E-learning is nothing more than the distribution of notes over the Internet ()

\section{THE END}

Thank you for sparing your precious time

Open Access Bioinformatics

\section{Publish your work in this journal}

Open Access Bioinformatics is an international, peer-reviewed, open access journal publishing original research, reports, reviews and commentaries on all areas of bioinformatics. The manuscript management system is completely online and includes a very quick and fair

\section{Dovepress}

peer-review system. Visit http://www.dovepress.com/testimonials.php to read real quotes from published authors. 